ISSN: 0213-2079 - ISSN electrónico: 2386-3889

DOI: http://dx.doi.org/10.14201/shhmo201537153181

\title{
«DONDE AY DAMAS, AY AMORES». RELACIONES ILÍCITAS EN LA CORTE DE FELIPE II: EL CASO DE DON GONZALO CHACÓN Y DOÑA LUISA DE CASTRO ${ }^{1}$
}

\author{
"Where there are Ladies, there are Love Affairs» Illicit \\ Relations in the Court of Philip II: the Case of Don Gonzalo \\ Chacón and Doña Luisa de Castro
}

\author{
Elisa GARCÍA PRIETO \\ Universidad de Lisboa \\ Correo-e: elisagarciaprieto@gmail.com
}

RESUMEN: En este artículo pretendemos analizar las relaciones ilícitas protagonizadas por damas de Palacio en la Corte de Felipe II. A través de los casos de doña Luisa de Castro -cuya historia constituye la pieza principal de la contribución- y de doña Magdalena de Guzmán, podemos analizar las estrategias femeninas en estos casos de «deshonor». Vamos a hacer una aproximación temática y no cronológica para entender mejor las implicaciones y estrategias desplegadas; así, vamos a prestar atención a los inicios de estas relaciones, los obstáculos a los que tuvieron que hacer frente y cómo, una vez que el escándalo fue notorio en la Corte, estas mujeres y su entorno desplegaron un buen número de estrategias para asegurarse una salida honorable.

Palabras clave: Corte de Felipe II; damas; galanteo; estrategias femeninas.

1. Esta investigación se inscribe en el proyecto «Prácticas y saberes en la cultura aristocrática del Siglo de Oro ibérico: comunicación política y formas de vida» HAR2011- 27177 financiado por el Ministerio de Ciencia e Innovación. 
ABSTRACT: In this article we intend to analyze the illicit relationships that some ladies in waiting maintained with gentlemen in the courtly space during Philip II's Reign. Through the cases concerning doña Luisa de Castro -whose history is the central piece of this contribution- and doña Magdalena de Guzmán, we can analyze the feminine strategies in these «dishonor» cases. We are going to make a thematically, and not chronologically, approach to better understand the implications and strategies displayed; so, we are going to pay attention to the beginning of the relationships, the obstacles they suffered and how, once the scandal was notorious in the courtly space, these women and their entourage displayed a good number of strategies to afford themselves and honorable solution.

Key words: Court of PhilipII; Ladies-in-Waiting; Courtship practices; Feminine strategies.

\section{INTRODUCCIÓN}

«Don Gonzalo Chacón comendador de la orden de Calatrava principal y deudo de muchos caballeros y señores de este Reino tuvo amores que no debiera en el año de 1572 con $\mathrm{D}^{\mathrm{a}}$ Luisa de Castro (...), dama de la Princesa doña Juana (...), y lo que entre ellos en fin pasó, ellos se lo saben...».

Así comienza la memoria sobre el negocio de don Gonzalo Chacón y doña Luisa de Castro de la que hoy día conservamos diversas copias manuscritas. Los amores ilícitos entre la dama y el galán generaron un gran escándalo en la Corte acrecentado tras la huida de don Gonzalo hacia la frontera francesa. Una vez apresado se abrió un pleito que, tras muchas idas y venidas, se finiquitó con una pena de destierro para los amantes. Este asunto, que concitó la atención de propios y extraños, no fue un caso aislado en la corte de Felipe II pues, pocos años antes, el hijo del gran duque de Alba, don Fadrique de Toledo, cayó en desgracia por unas circunstancias similares al mantener una relación amorosa con doña Magdalena de Guzmán, dama de la reina Isabel de Valois. Estos casos notorios nos permiten realizar una lectura diferente de la Corte de Felipe II, podríamos llamarlo una crónica escandalosa del reinado, pero sin duda ello nos permite ahondar en muchos más aspectos. Si bien nos interesa destacar la idoneidad de estos asuntos para conocer las costumbres de la Corte, también queremos destacar el componente humano de los mismos; en definitiva, saber cuáles fueron las motivaciones que llevaron a sus protagonistas a actuar de la manera que lo hicieron, y lo vamos a hacer poniendo especial énfasis en los comportamientos de las protagonistas femeninas.

Si bien es cierto que contamos con un cada vez mayor número de estudios sobre los personajes de la Corte, lo cierto es que queda mucho por conocer, especialmente 
cuando nos referimos a "colectivos» como los de las damas. Conocemos con bastante detalle las mujeres que sirvieron a la Familia Real durante estos años, merced a la detallada documentación administrativa que ha sobrevivido en los archivos, pero evidentemente esta no ofrece una información muy pormenorizada de cada una de estas mujeres, pues para ello debemos complementarla con otras fuentes como epistolarios, memorias, etc. Hechos notorios como los que vamos a referir constituyen una anomalía que resulta de enorme interés al historiador; la gravedad de estos episodios ponía en marcha una maquinaria -en este caso de tipo judicial- que se ha traducido en la generación de una documentación de enorme valor por la cantidad de datos y detalles sobre las vidas de personas particulares. En el caso concreto que vamos a tratar contamos con las confesiones, trámites y condena en el caso de don Gonzalo y doña Luisa, además de los papeles de Martín de Gaztelu sobre la resolución del conflicto y diversos memoriales de la madre y hermana de Don Gonzalo. Asimismo, los papeles de Patronato Eclesiástico -concretamente las consultas del Presidente Pazos a Felipe II- han sido la fuente fundamental que los historiadores han usado para conocer el caso de doña Magdalena y Don Fadrique, así como las gestiones del duque de Alba para evitar la conclusión de este matrimonio. A ello hay que añadir los memoriales que la hermana de Doña Magdalena elevó a Felipe II y las cartas que don Juan de Zúniga envío a la misma. En definitiva, se trata de un corpus complejo y variado que nos ha permitido reconstruir los hechos y reflexionar sobre los medios usados por sus protagonistas para defender sus intereses.

La vida de las damas se ha estudiado desde los textos normativos que regulaban sus vidas, testimonios literarios que nos hablaban de las máscaras y comedias que representaban a los ojos de la Corte y, a través de las noticias breves que apuntaban sus matrimonios, sus entradas en conventos o sus muertes en plena juventud; los desafíos a esta vida reglada y ordenada quedaban simplemente mencionados en textos o romances con un punto moralizante cuando no idealizado. En definitiva, la vida de las damas sigue siendo, en muchos casos, una incógnita para aquellos que se acercan al mundo de la Corte. A veces parece que las imágenes arquetípicas se suceden una y otra vez, sin llegar a reparar en que detrás de ese «colectivo» hay vidas particulares e intereses personales cuyo conocimiento es esencial si queremos avanzar en nuestra comprensión de las sociedades pasadas. Asimismo, creo que ofrecen un campo de estudio interesantísimo para la historia de las mujeres². Pertenecientes, en

2. Existen diversos estudios sobre las damas de Palacio y así destacan las aportaciones de López Cordón Cortezo M. V.: «Entre damas anda el juego: las camareras mayores de Palacio en la Edad Moderna", Cuadernos de Historia Moderna, Anejo II, 2003, pp. 123- 152. Asimismo, las diferentes aportaciones que encontramos en Martínez Millán J. y Lourenço M. P. (coords.): Las relaciones discretas entre las Monarquias Hispana y Portuguesa: las Casas de las Reinas (siglos XV-XIX). Madrid, 2008, pp. 1357- 1397. 
muchos casos, a linajes aristocráticos, insertadas en redes familiares y clientelares, su paso por las casas reales constituía no solo un entrenamiento adecuado para sus futuras labores, sino también la vía a través de la cual podían alcanzar una posición favorable para la defensa de los intereses familiares. Frente a las restricciones que las etiquetas de Palacio imponían a las damas, la realidad fue mucho más flexible, y las conexiones que se realizaban dentro de las residencias regias beneficiaban a estas mujeres y a su círculo más próximo, que en muchas ocasiones también estaba integrado dentro de la servidumbre palatina. Los casos de doña Magdalena y doña Luisa nos sitúan en un escenario excepcional y, en principio, con una serie de obstáculos que a priori les tendría que haber dificultado la consecución de una salida honrosa. Como vamos a ver a continuación, la documentación manejada nos demuestra que ambas damas, y su círculo más cercano, pudieron establecer una serie de estrategias para, en circunstancias adversas, defender los intereses de ambas mujeres. Un hecho que queremos resaltar en este aspecto es el papel jugado por las propias damas, pero también por otras mujeres cercanas a las mismas o afectadas por los hechos. Así, en el caso de doña Magdalena de Guzmán, la figura de su hermana, doña Brianda, va a tener un peso esencial y los memoriales escritos de su mano son una fuente interesantísima para poder reconstruir diversos aspectos del escándalo. En el caso de doña Luisa, nos queremos referir al papel jugado por la madre y la hermana de don Gonzalo, doña María y doña Luisa, integradas en la Casa de la Reina y si bien sus acciones no estarían destinadas a defender los derechos de la dama en cuestión, nos remiten a la importancia del papel femenino en estos casos.

No quiero dejar de señalar que además de ser un indicativo de cómo actuaban y se movían estas mujeres en el universo cortesano, también nos sirve para comprender mejor las relaciones entre ambos sexos. Si bien es cierto que la servidumbre femenina de las casas - de la Reina y otras mujeres de la realeza, como es en este caso la de la Princesa- tenía unos límites establecidos que trataban de evitar la intromisión de los varones (o la de ellas en los espacios masculinos), la utilización de plazas comunes hacía que la ambos grupos se mezclaran y relacionaran. Más allá de la práctica del galanteo, las mujeres que conformaban la servidumbre palatina establecían relaciones de diversa naturaleza con miembros del sexo opuesto, y en ocasiones los lazos se estrechaban en relaciones más íntimas como las que unieron a los protagonistas de estos episodios. El hecho de que casos como los que vamos a tratar saltasen a la esfera del conocimiento público, nos permiten entrever el modo en que hombres y mujeres convivían, socializaban e interactuaban en un espacio común, lo que nos permite avanzar en nuestro conocimiento sobre este complejo mundo de la Corte ${ }^{3}$.

3. La historiografía inglesa ha prestado bastante atención a los comportamientos sexuales ilícitos de los miembros de la elite. En este sentido resulta sugerente la apreciación de Paul E. J. 
ELISA GARCÍA PRIETO

«DONDE AY DAMAS, AY AMORES». RELACIONES ILÍCITAS EN LA CORTE DE FELIPE II: EL CASO DE DON GONZALO CHACÓN Y DOÑA LUISA DE CASTRO

\section{DRAMATIS PERSONAE}

Antes de iniciar el análisis de los hechos y reacciones que provocó el escándalo protagonizado por don Gonzalo Chacón y doña Luisa de Castro es conveniente realizar un pequeño bosquejo biográfico de estos dos personajes. Si bien es cierto que su caso no ha pasado totalmente desapercibido para los historiadores, no resulta tan conocido como el otro que traemos como comparativa: el que afectó a don Fadrique de Toledo 4 y a doña Magdalena de Guzmán 5 . No obstante, podemos dar unos datos básicos sobre ambos personajes. Así, de don Gonzalo Chacón', que fue hijo de don Hernando de Rojas, mayordomo del Príncipe don Carlos, y de doña María Chacón ${ }^{7}$, aya de las infantas y el Príncipe D. Fernando. Fue caballero de la orden de Calatrava, gozando, merced a esa condición, la encomienda de Almodóvar del Campo. Por los testimonios que hemos manejado entendemos que tuvo participación en la Guerra de las Alpujarras, así como una presencia activa en los círculos cortesanos, donde su madre y hermana ${ }^{8}$ cumplían con oficios

Hammer cuando afirma lo siguiente: «Looking at sexual behavior at court, and specially instances of promiscuity there -that is, sexual relations outside the legally and socially sanctioned boundaries of marriage- can provide interesting anecdotal evidence about gender ralations among the aristocratic elite», Hammer P. E. J.: «Sex and the Virgin Queen: Aristocratic Concupiscence and the Coirt of Elizabeth I», Sixteenth Century Journal, XXXI: 1, 2000, pp. 77-97, p. 79. Para un estudio de caso en la Ingatera isabelina: Wall, A.: «Love, Money or Politics? A Clandestine Marriage and the Elizabethan Court of Arches», The Historical Journal, 38:3, pp. 511-533.

4. Sobre don Fadrique de Toledo, Colección de Documentos Inéditos para la historia de España, volúmenes VII y VIII. Véase también Martínez Hernández, S. «Estrategias matrimoniales en tiempos de disfavor regio: juicio, prisión y muerte de don Fadrique de Toledo, IV duque de Alba, 1574-1585» en Ser Quijano, G. (coord.): Congreso V Centenario del III duque de Alba, Fernando Álvarez de Toledo, Salamanca 2008, pp. 499- 523. Asimismo, breves semblanzas sobre el personaje en las biografías sobre don Fernando Álvarez de Toledo, destacando las de Maltby, W. S.: El gran duque de Alba. Gerona, 2007 (1a ed. en 1983) y Kamen, H.: El gran duque de Alba. Soldado de la España Imperial. Madrid, 2005.

5. Sobre Magdalena de Guzmán: Fernández Martín, L.: «La marquesa del Valle. Una vida dramática en la Corte de los Austrias» en Hispania, 39, 1979, pp. 559- 638; Olivari, M.: «La marquesa del Valle: un caso de protagonismo político femenino en la España de Felipe III», Historia Social, n. ${ }^{\circ}$ 57, 2007, pp. 99- 126; y su caída en desgracia durante el reinado de Felipe III en Sánchez, M.: The Empress, the Queen and the Nun. Women and Power at the Court of Philip III of Spain. Baltimore, 1998, pp. 100-101; Williams, P.: El gran valido. El duque de Lerma, la Corte y el gobierno de Felipe III. 1598-1621. Valladolid, 2010, pp. 138-141; Feros A.: El duque de Lerma. Realeza y privanza en la España de Felipe III. Madrid, 2002, pp. 182 y 183; y Martínez Hernández, S.: Rodrigo Calderón. La sombra del valido. Privanza, favor y corrupción en la corte de Felipe III. Madrid, 2009, pp. 96- 97.

6. En algunas obras sobre la Corte de Felipe II se suele confundir a este don Gonzalo con su primo, don Gonzalo Chacón, I conde de Casarrubios, caballerizo mayor de la Reina Ana de Austria.

7. Sobre la familia Chacón véase Asturias Ilustrada. Primitivo Origen de la Nobleza de España (...) su autor Don Joseph Maniel Trellesvilla de Moros, tomo III. Madrid, 1760, p. 375.

8. Isabel Chacón fue recibida como dama de la reina Ana de Austria en 1570 y casó en 1580 con su primo don Gonzalo Chacón, caballerizo de la reina y primer conde de Casarrubios del Monte. AGP, Personal, caja 16825, exp. 24. 
dentro de la Casa de la Reina; él mismo había ocupado puesto de paje en las casas del príncipe don Carlos y de la Reina Isabel de Valois, y en el momento de los hechos era gentil hombre de la Boca en la Casa de Felipe II ${ }^{9}$. Tras su azarosa y fallida huida hacia Francia, tuvo que cumplir pena de destierro en Portugal junto a su mujer. Su presencia en la expedición de Alcazarquivir queda confirmada por algunas crónicas que relatan su muerte heroica al lado del monarca portugués ${ }^{10}$.

Poco es lo que por el momento conocemos de doña Luisa de Castro; en la confesión de la dama ni siquiera se nos dice la edad, si bien suponemos que estaría cercana a la veintena. Hija de don Francisco de Cisneros y de doña María de Castro, estaba emparentada por parte de madre con el Caballerizo Mayor de la Reina, don Luis Venegas, ya que la mujer de este, doña Guiomar de Sa, era hermana de aquella. No hemos encontrado demasiadas noticias sobre los pasos que siguieron los deudos de doña Luisa por su defensa, aunque no podemos descartar que no hiciesen alguna petición al Rey a favor de la dama ${ }^{11}$. Tampoco sabemos mucho más de la vida de doña Luisa en el destierro; de su matrimonio con don Gonzalo nacieron dos hijos ${ }^{12}$, pero poco sabemos de cuál fue su trayectoria tras la muerte de su marido o si quiera, si le sobrevivió

\section{EstRATEgIAS FEMENINAS EN CASOS DE DESHONOR}

Más allá de las similitudes entre los dos casos a analizar, por lo que toca a su condición de relación prohibida, lo que nos interesa destacar aquí son las estrategias y medios

9. Martínez Millán J. y Fernández Conti S. (dirs.): La Monarquía de Felipe II: la Casa del Rey, vol. II. Madrid, 2005.

10. «Esto fue la mayor lástima de todas, porque se quedó el Rey perdido y desamparado, con algunos pocos suyos de los más leales y cuidadosos que jamás se le despegaron, y con un renegado que procuró salvarle, principalmente don Gonzalo Chacón, caballero castellano hermano del arzobispo de Toledo don Bernardo de Rojas, Cardenal de España, que allá andaba desterrado por el Rey Católico, lo hizo tan valerosamente, que jamás le perdió de su lado, y al fin murió como buen caballero junto a su misma persona» en SAN Román, fray Antonio de, Iornada y muerte del Rey Don Sebastián de Portugal, sacada de las obras del Franchi ciudadano de Génova y de otros muchos papeles auténticos, Valladolid, 1603 (herederos de Juan Yñiguez de Lequerica), pp. 160-161.

11. Sí que hemos encontrado una noticia sobre don Francisco de Cisneros que se conserva entre los papeles del Consejo de Órdenes acerca de un pleito que hubo entre este caballero y su hija tras los acontecimientos que estamos narrando. No obstante no sabemos, por el momento, la naturaleza del pleito y cuál fue el resultado, si bien es cierto que podría ser una vía para indagar en el devenir de la vida de la dama tras su destierro de la Corte. BL Add Mss 28364, fol. 133.

12. Este dato lo tomamos de la correspondencia de doña Ana de Dietrichstein, dama también de la princesa doña Juana, a su madre doña Margarita de Cardona. Agradezco a Vanesa de Cruz la consulta de este material en fase de publicación. «Doña Luysa de Castro está muy contenta y con toda su pobresa, tiene una yja y está para parir» San Lorenzo del Escorial, 3 de Septiembre de 1576, Carta XXI en Cruz Medina V.: Cartas de Ana de Dietrichstein a su madre, Margarita de Cardona: una doncella en la Corte de Felipe II (1573/4-1581), trabajo de investigación inédito. Madrid, 2002, p. 59. 
concretos que emplearon ambas mujeres para tratar de defender sus intereses. Si bien es cierto que los límites cronológicos entre uno y otro no coinciden, creo que resulta muy interesante su análisis conjunto ya que este nos permitirá englobar las analogías entre uno y otro.

A pesar de que las etiquetas de palacio trataron de marcar unos límites muy estrictos para la vida de las damas, lo cierto es que estas mujeres debieron contar con una mayor libertad de movimiento de la que aquellas nos sugieren. La práctica del galanteo era muy frecuente y ha quedado perfectamente documentada en los relatos de los viajeros ${ }^{13}$ y también a través de la publicación de obras que tenían como fin el ofrecer una «guía» con recursos dialécticos para damas y galanes ${ }^{14}$. No podemos olvidar tampoco los comentarios que al respecto hicieron algunos de los cortesanos que se movieron en los ámbitos palaciegos durante el reinado de Felipe II. Si nos atenemos a las palabras que el conde de Portalegre dirigía a una dama, el galanteo era una práctica no solo habitual, sino que requería de unas habilidades especiales que permitían al perfecto cortesano triunfar en ese particular ámbito ${ }^{15}$. Don Fadrique y don Gonzalo se movían en los círculos cercanos a estas damas en virtud de sus puestos dentro de las casas reales así como al parentesco con destacados miembros de las casas regias; ello les permitió compartir momentos con las damas y «actuar» como galanes. El galanteo era una costumbre más dentro de los usos cortesanos, y no necesariamente debía cuajar en una relación más profunda que finalizase en matrimonio. Es más, los enlaces de las damas respondían a unas

13. «Junto a la reina iban seis damitas de muy alta nobleza, tres de las cuales la sirven a la mesa con mucho respeto, mientras que las otras apoyadas en los muros de la habitación, charlaban con sus novios o galanteadores (así es como los llamaban) de cosas divertidas. Estos galanteadores tienen la libertad de cubrirse delante del rey y de la reina con tal que estén conversando con la señorita a quien sirven; son príncipes o señores distinguidos por su riqueza y su nacimiento; sirven a las damas para pasar el tiempo de una manera agradable, para ver a menudo a Su Majestad y con la intención también de tomarlas por esposas. Si tuvieran otros proyectos, se verían decepcionados porque las reglas del Palacio de su Majestad son muy estrictas en ese punto» Relación de la Corte de España en Alvar Ezquerra, A.: La villa de Madrid vista por los extranjeros. Madrid, 1990, p. 27.

14. Nos referimos a la obra de Luys de MiLÁn Libro de motes de damas y canalleros, intitulado el juego de mandar, Valencia 1535, y hecho para la corte virreinal de doña Germana de Foix y Fernando de Calabria. Hay edición crítica, Vega VÁzquez, I. (ed.): El libro de motes de damas y caballeros de Luis de Milán. Santiago de Compostela, 2006.

15. En una carta a doña María Manuel, don Juan de Silva habla de su ignorancia juvenil en estos temas y cómo se hace enseñar de otros caballeros más experimentados en estas lides: «De esta confusión, que no podía ser mayor, me han sacado los galanes viejos de los que aún [n]o comienzan a caducar y ambos afirman que aún [n]o estoy doliente de desdicha sino de ignorancia porque ni he sabido acomodarme a creer y a decir mentiras: me escandalicé(...) y ellos se rieron, tornando a decir que me desengañase porque el trato de las Damas anda sobre dos ruedas, que la una era hacer engaño y la otra disimularlos» Correspondencia de don Juan de Silva con varios personajes, BNE Mss/1439, fols. 111r- 112v. 
estrategias perfectamente orquestadas por sus deudos que tenían, además, el visto bueno del Rey ${ }^{16}$.

Lo que hace que estos amoríos se convirtiesen en casos notorios fue que los vínculos que se establecieron entre ellos derivaron en una relación más profunda que quisieron formalizar a través del matrimonio. El desafío, ahora, es reconstruir todo el proceso hasta culminar en el momento del «escándalo» propiamente dicho. Sabemos, por los testimonios de la hermana de doña Magdalena-que más adelante analizaremos con detalle- que don Fadrique dio promesa de matrimonio a la dama y que esta, al «publicitar» su ventajoso compromiso, desencadenó el proceso que acabó con el destierro del galán y su propio encierro en Toledo. El caso de don Gonzalo y doña Luisa nos ha ofrecido, por el momento, más testimonios anteriores que nos permiten comprender de una manera más profunda el desarrollo de su relación; nos vamos a centrar en él para poder ver las diferentes perspectivas que un caso de esta notoriedad ofrece. En efecto, al leer el proceso a que fueron sometidos ambos, encontramos una multitud de noticias, procedentes de los diferentes testigos que tuvieron que testificar, y que nos hablan de la existencia de un vínculo fuerte entre ambos mucho antes de la huida. Parece que la relación entre el caballero y la dama al servicio de la princesa era suficientemente conocida y de ahí que en el año 1570 en el contexto de la guerra de Granada, el marqués de Ladrada, mayordomo mayor de la reina doña Ana de Austria, recibiera la siguiente información para transmitírsela a doña Luisa:

Lo de Granada va muy cuesta abajo como v. m sabrá por otros coronistas. Don Gonzalo Chacón a peleado muy valientemente, quedó herido en una pantorrilla mas fue muy poco, sépalo la señora doña Luisa de Castro ${ }^{17}$.

Cronológicamente la noticia es creíble, ya que la propia dama en su confesión alude al momento de inicio de su relación con don Gonzalo. Ella afirmó que ambos se conocían desde largo tiempo atrás - diez años antes de los sucesos, cuando entró en la Casa de la Princesa, muy posiblemente como menina- y que se habían tratado como galán y dama desde tres años antes al momento de su huída, por lo tanto, en torno al año de 1569. Desde ese momento ambos se

16. Una de las ventajas de ser dama en Palacio era el llamado «cuento de dama»; este servía para complementar la dote que aportaban al matrimonio. La intervención regia no se limitaba únicamente a este tipo de mercedes, sino que además, el monarca y su consorte favorecían determinado tipo de alianzas y eran parte necesaria en la aprobación de los enlaces de estas mujeres. Este punto es esencial para entender el tipo de conflicto que estamos describiendo y que no fue un caso aislado en la Corte de Felipe II. Para un análisis pormenorizado de las alianzas matrimoniales protagonizadas por las damas véase García Prieto E.: La infanta Isabel Clara Eugenia de Austria, la formación de una princesa europea y su entorno cortesano. Madrid, 2012, especialmente el apéndice I, 471-495.

17. Carta al marqués de Ladrada, 1570, BL Add. Mss 28354, fol. 27. 
comportaron de una manera que les señalaba como tales: conversaciones a la vista de otros cortesanos y otras algo más clandestinas «por agujeros de puertas y otras partes» ${ }^{18}$, intercambio de cartas y billetes que implicaban a otros miembros de la servidumbre palatina, etc. Podemos hacernos, entonces, una idea de cómo el entorno que rodeaba a doña Luisa y don Gonzalo fue consciente de su relación y de los problemas que ello implicaba. En los testimonios de personas destacadas dentro de la Casa de la Princesa y la Reina -nos referimos en concreto a los del doctor Almazán, don Cristóbal de Moura y don Luis Venegas- vemos incluso el reproche hacia la actitud descuidada que mantenían los protagonistas del episodio y es que, eran muchos los obstáculos que tuvieron que afrontar a lo largo de su relación y el más importante de ellos, la imposibilidad de ver cómo el galanteo se consolidaba en una relación matrimonial aceptada por su entorno. don Gonzalo y doña Luisa vieron en sus promesas mutuas razón suficiente para afirmar su estado matrimonial, un hecho que a su juicio justificaba muchas de las acciones que posteriormente se les echaron en cara como faltas graves. En este sentido, también habría que analizar el valor de la promesa que don Fadrique hizo a doña Magdalena y hasta qué punto les comprometía. Pero primero vamos a ir analizando los factores que hicieron de estas relaciones un problema para sus protagonistas y aquellos que les rodearon

\section{I. La oposición al matrimonio: el papel de la familia}

Sin duda, uno de los hechos que no podemos pasar desapercibidos fue la oposición de los deudos, tanto en el caso de don Gonzalo como en el de don Fadrique. Así, en el primero de ellos, son frecuentes las alusiones en el proceso a la firme oposición de la madre de don Gonzalo, María Chacón. Como ejemplo podemos traer aquí la declaración de Juan Gómez de Saravia, aposentador en la casa de la Princesa de Portugal, y en la que se explicita lo siguiente:

oía este testigo decir en Palacio a personas que no se acuerda que la madre del dicho don $\mathrm{G}^{\circ}$ no lo consentía.

Esta oposición, cuya existencia se repite a lo largo del proceso, fue clave a la hora de entender las conductas posteriores de don Gonzalo y doña Luisa, ya que trataron por todos los medios de legalizar su unión sin tener que contar con el preceptivo permiso familiar. Este mismo rechazo lo podemos vislumbrar, a la luz de los acontecimientos posteriores, en el caso de doña Magdalena de Guzmán y don Fadrique de Toledo. Este negocio se complicó sobremanera al producirse el

18. Confesión de Juan Gómez Saravia en Causa de D. Gonzalo Chacón, AHN, Órdenes Militares, Archivo Histórico de Toledo, leg. 36634, s. f. 
precipitado matrimonio entre don Fadrique y doña María de Colonna y Toledo, su prima carnal, unión que respondía claramente a los intereses familiares y dinásticos de la familia Alba. Este es un hecho que no puede pasar desapercibido y en el que estos dos casos confluyen. Si bien es cierto que estamos hablando de personajes que se mueven dentro del mismo grupo cortesano, tenemos que ser conscientes de las diferencias notables de linaje entre las damas y sus galanteadores. Es cierto que en el caso de doña Luisa no debemos despreciar su ascendiente -era nieta de un Jiménez Cisneros-y los vínculos con personajes destacados de la Corte, pero don Gonzalo contaba con una parentela más poderosa en el ámbito cortesano, así como en otras instancias. En el caso de doña Magdalena, si bien contaba con vínculos de renombre en la Corte, no gozaba de un ascendiente que tentase al duque de Alba para unirla a su hijo y heredero ${ }^{19}$; de hecho, las gestiones de la familia de la dama van a ser impotentes ante la capacidad de maniobra que tenía de facto la Casa ducal. No obstante, también tenemos que analizar esta diferencia desde otra perspectiva y, en este sentido, podemos suponer que tanto una como otra tenían mucho que ganar de concretarse las uniones con sus galanes ${ }^{20}$. Este hecho no pasó desapercibido a los instructores del juicio contra don Gonzalo Chacón tal y como podemos constatar en una de las preguntas:

si saben que a la dicha doña Luisa de Castro le estaba y estuvo muy bien el dicho casamiento que así concertó de hacer con el dicho don Gonzalo Chacón y ella lo tenía por muy aventajado para sí y por la calidad del dicho don Gonzalo y por esto se mostraba tan aficionada y deseosa de ver publicado y solemnizado el dicho matrimonio.

19. En el pleito, también por cuestiones matrimoniales, que ocupó al V duque de Alba, se hacía la siguiente observación «El Prior [don Fernando de Toledo] dice, como habiéndose desconcertado el casamiento de su hija del duque del Infantado, y que estaban resueltos de no tratar más del, representó el Duque su sobrino, que en España había cuatro señoras tan buenas como él, con quien podría casar...» Relación del Pleito que por particular breve de la Santidad de Gregorio XIIII se trata en la causa matrimonial entre don Antonio Álvarez de Toledo duque de Alba, y doña Catalina Cortes de Ribera, hija del duque de Alcalá y doña Mencía de Mendoza y de la Vega, hija del duque del Infantado, y marqués del Cenete que a este pleito fue llamada, RBME, 33- I- 9, n. ${ }^{\circ} 12$, s. f. La aseveración de que solo cuatro mujeres estaban a la altura de un matrimonio con el duque de Alba es bastante significativa, y posiblemente también estaba en la mente del entonces III Duque al pensar en una alianza para su hijo y heredero.

20. Los beneficios del matrimonio para las damas las presenta bajo una óptica que dista mucho de la de víctimas; $y$ es que debemos de tener en cuenta que el matrimonio era sobre todo un contrato más que tenía como fin la preservación de un patrimonio o la consecución de otro, y estas damas no eran ajenas a este hecho. Otros estudios centrados en matrimonios aristocráticos también han incidido en este aspecto como es el caso de DADson, T. J.: «Un poeta del amor y los amores de un poeta: Diego de Silva y Mendoza, conde de Salinas (1564- 1630)» en Cerdan, F.: Hommage à Robert Jammes, Toulousse, 1994, pp. 299-311. 
Más allá de lo sugestivo de la propia pregunta, lo interesante es la percepción que algunos miembros de la Corte tuvieron de este particular aspecto. Uno de los testigos aportados por la parte de don Gonzalo, en concreto Alejo de Teves, corrobora ese hecho

...dijo que este testigo sabe que la dicha doña Luisa le estaba muy bien el casamiento con el dicho don $\mathrm{G}^{\circ}$ porque le tenía por honrado caballero e tan bien nacido como ella e tenía de comer, e que a la dicha doña Luisa le oyó decir este testigo que deseaba se efectuase el dicho casamiento.

Algo que no podemos pasar inadvertido en el análisis de las motivaciones de esta mujer a la hora de defender su honra. A través de las confesiones entre ambos podemos vislumbrar el buen entendimiento y sentimientos que existían entre don Gonzalo Chacón y doña Luisa de Castro, pero no por ello la relación estaba exenta de razones de tipo más material. La dama, si bien es cierto que contaba con la posición social que le suponía su condición de servidora de Palacio y los beneficios anejos a ello, debía asegurarse una unión provechosa. Sabemos, por la declaración de otro testigo, que en Palacio circulaba la noticia de los proyectos para unir en matrimonio a la dama con don Pedro Niño, que, por razones que no podemos concretar, o no gustó a doña Luisa o bien nunca fue un proyecto en firme ${ }^{21}$. El caso es que parece que la posición de don Gonzalo constituía un aliciente para ella. El obstáculo más grave que podían encontrarse en este sentido era la oposición paterna y, por supuesto, la del rey, quien tenía un papel clave en la resolución de estos negocios. La consideración de sus promesas como un matrimonio en firme es un elemento que se repite tanto en la confesión de don Gonzalo como en la de doña Luisa; este hecho les sirvió para justificar a posteriori muchas de las acciones que cometieron y que tenían un claro carácter ilícito. No debemos pensar que ambos cometían una impostura a la hora de defender la existencia de un matrimonio, ya que tiene una base real que se corroboró, para sus contemporáneos, en el comportamiento que mostraban el uno con el otro. Como en una letanía, a lo largo del proceso se van repitiendo las declaraciones de esas muestras conyugales que se prodigaban don Gonzalo y doña Luisa y que quedaban expresadas por multitud de gestos. Asi podemos señalar cómo se enviaban billetes y recaudos en los que don Gonzalo le decía a la dama «...que no comiese cosas malas y que la hiciesen mal» siendo, según este testigo -Francisco de Oviedo, portero de la cámara de la Reina Ana- «recaudos como de marido a mujer». Por su parte, María de Castilla, mujer del Adelantado de Canarias dejaba dicho en su testimonio que «... Don $\mathrm{G}^{\circ}$ Chacón trataba de casarse con ella y la llamaba mujer

21. Este don Pedro Niño fue uno de los mayordomos semaneros de la reina doña Ana. AGP, Personal, caja $16825 / 18$ y caja 742, n. $^{\circ} 28$. 
y ella se tenía por tal (...) y daba muestras de tenerse por su mujer, recatándose de no hacer cosa contra la voluntad de don $G^{\circ}$ ». La convicción de la existencia de tal vínculo llegó a generar habladurías en el seno de la casa de la Princesa y así, la mujer de Pablo de Medrano -contador de la Casa de la Princesa doña Juana-, doña Isabel de Solórzano, comenta que «decían que era dama impedida, dando a entender que ya era casada...». A pesar de ello, era necesario legalizar la unión -que algunos testigos creían ya celebrada en Getafe, con ocasión de una de las salidas de la Corte hacia Aranjuez- y vencer, en principio, las prevenciones que ante tal matrimonio tenía la familia de don Gonzalo.

La oposición familiar y el deseo de formalizar la unión a pesar de las trabas nos remite a un hecho fundamental que es la transformación del sacramento matrimonial como consecuencia del Concilio de Trento. No es nuestro objetivo tratar pormenorizadamente este aspecto, pero sabemos que uno de los efectos de Trento fue el estricto control sobre la institución matrimonial. El permiso paterno se convirtió en preceptivo para consumar la realización de los matrimonios que aparecen así, como una estrategia familiar más para consolidar el poder político, económico y social ${ }^{22}$. La familia de don Gonzalo debía tener en mente otras uniones más provechosas para su vástago, y doña Luisa de Castro no entraba en tales planes. Los dos protagonistas contaban con otras salidas para formalizar su relación. Una de estas vías consistía en jugar con la idea de que su compromiso verbal era suficientemente vinculante como para considerarse verdadero matrimonio. No podemos ponderar hasta qué punto ellos «creían» en la validez de este proceso, pero lo que si podemos constatar son las frecuentes alusiones a ello ${ }^{23}$. Doña Luisa, en su confesión, relata de manera muy pormenorizada la profundidad del vínculo que había desarrollado con don Gonzalo, y en ningún momento se avergüenza de ello puesto que declara, convencida, que ellos eran marido y esposa. También don Gonzalo hace alguna alusión al respecto y en su confesión son muchas veces en que se refiere a doña Luisa como «mi mujer». Esto no elimina la otra vía de la que, en principio, disponían y que consistía en lograr una dispensa papal que

22. Para una visión comparativa de las consecuencias de Trento en los países católicos véase Sperting J.: «Marriage at the Time of the Council of Trent (1560-1570): Clandestine Marriages, Kinship Prohibitions, and Dowry Exchange in European Comparison», Journal of Early Modern History, 8:1-2, pp. 67-108.

23. Si bien no podemos entrar de manera detallada en ello, otros casos similares que tuvieron lugar en el mismo periodo cronológico nos ayudan a comprender más claramente las implicaciones legales que tenían estas promesas de matrimonio. En concreto, el duque de Feria se vio envuelto en un conflicto similar en su enlace con la hija de la marquesa de Elche. El duque de Nájera alegó que había habido conversaciones para que matrimoniara con su hija, pero habiendo dado palabra de matrimonio a la hija de la marquesa de Elche se determinó que el cumplimiento de esta última invalidaba los acercamientos entre Nájera-Feria. Contamos con varios memoriales al respecto en BL, Add Mss 28339. 
les exonerase de contar con el buen parecer de los deudos del caballero. Como veremos más adelante, doña Luisa presionó a su galán para conseguir que realizara estas gestiones, algo que don Gonzalo hizo - como se confirma en su confesión que queda corroborada por otros testigos-y de lo que quedó constancia a las personas del Consejo de Órdenes que juzgaban el caso, ya que el caballero hizo firmar a doña Luisa un pliego en blanco para el trámite pertinente ${ }^{24}$.

\subsection{Estrategias femeninas}

Uno de los puntos que pretendemos analizar aquí es el papel jugado por las protagonistas de estas historias palaciegas. Frente a la idea de la pasividad femenina que determinadas obras han tratado de transmitir, podemos vislumbrar en estos casos particulares cómo las mujeres del siglo xvi contaron con estrategias y medios para defender sus intereses personales, si bien es cierto que no siempre surtieron los efectos deseados. La divergencia en las fuentes no nos permite tener testimonios similares en todos los casos, pero creo que cada una de las documentaciones aportadas nos permite ver cómo se desenvolvieron estas damas y cómo presentaron sus casos.

El proceso contra don Gonzalo Chacón es, en este sentido, una fuente muy rica en noticias y pareceres, ya que al contener en sí misma diversos testimonios que abarcan a las personas que rodearon a la dama y su galán, podemos recopilar un gran número de visiones, además de poder reconstruir la relación desde sus inicios y no solo en un momento preciso. Refiriéndonos a la confesión de la propia doña Luisa de Castro debemos ver en ella no solo la narración de los hechos por parte de la protagonista femenina, sino también la visualización y opinión que, de los mismos, tuvo la dama. Pero yendo a lo que podríamos considerar como «estrategias femeninas» podemos ver cuáles fueron las empleadas por la dama para conseguir los diferentes fines. Hemos señalado con anterioridad los obstáculos a que tuvo que enfrentarse en su relación con don Gonzalo, siendo la oposición familiar uno de ellos, cuya resolución pasaba por complicadas gestiones por parte del caballero. Junto a ello hubo otros motivos de desencuentro que doña Luisa solventó con la amenaza de acabar con la relación. Efectivamente, en un momento de su confesión la dama hace alusión a una pequeña pelea que tuvo con don Gonzalo tras haberle prometido este que iban a casarse e iniciar una relación donde jugaban el papel de marido y mujer, con las restricciones que esto suponía -«le tenía esta confesante mucho respecto y seguía en todo su voluntad

24. «Preguntado si este confesante hizo que la dicha doña Luisa de Castro hiciese una firma en blanco y la hizo, de suerte que arriba se pudiese escribir lo que quisiese y para qué efecto se la hizo hacer...» Confesión de don Gonzalo Chacón en Causa de don Gonzalo Chacón, op. cit., s. f. 
dejando de hablar a quien el dicho don Gonzalo mandaba que no hablase»-. El desencuentro se produjo por los hechos siguientes:

esta confesante dijo a doña Juana de Tábara dama de la serenísima princesa que enviase por un capón de la cena del Rey a don Rodrigo de Mendoza de la cámara de su Majestad para hacer a media noche, el cual recaudo llevó un paje de don Cristóbal de Mora que se dice Pimienta, el cual en nombre de esta confesante pidió el capón al dicho don Rodrigo y no le trujo porque no le había y esto vino a noticia de don Gonzalo (...) el cual, enojado de ésto estuvo algunos días que no quiso hablar a esta confesante.

Ante lo que ella debía de considerar un trato poco justo por parte de don Gonzalo, doña Luisa amenazó con «acabar con el dicho don Gonzalo y tomar resolución de casamiento o meterse monja», un hecho definitivo que acabó por consolidar definitivamente la relación. De la promesa doña Luisa logró de su galán la acción, ya que este se comprometió a hacer las gestiones necesarias para legalizar una situación que ambos consideraban real «de facto». La dama debía ser bien consciente de que eran muchos los impedimentos que podían dar al traste con tan favorable unión, por lo que se valió de ese desencuentro para forzar de manera más definitiva la voluntad de don Gonzalo, quien en un momento dado podía sucumbir a las presiones familiares. El resultado fueron las pláticas con el tío de la dama, don Luis Venegas, con el Mayordomo de la Casa de doña Juana, don Cristóbal de Moura, y con el confesor de la Princesa, fray Juan de Vega, con lo que el asunto de su compromiso se publicitaba y, sobre todo, se hacía partícipe del mismo a personas con un rango elevado dentro del personal palatino que, en un momento dado podían defender los deseos de ambos ante la princesa doña Juana y por extensión ante Felipe II. Por tanto, quizá no debamos ver ese «berrinche» de doña Luisa como una respuesta irracional y «femenil» tras su enfado, sino como una acción más calculada y con intenciones más profundas.

En este punto sería interesante contar con más testimonios que nos ilustren sobre el proceder de doña Magdalena y don Fadrique en su faceta de galán y dama cortejada, y, sobre todo, de cómo ambos llevaron su relación personal. No podemos hacer una extrapolación con el caso de don Gonzalo y doña Luisa, entre otras cosas porque don Fadrique, que contaba con una experiencia vital más dilatada, se comportaría de un modo diferente al de su homólogo. Contamos con los testimonios escritos de doña Magdalena y dirigidos a Felipe II, que, podemos ver como una vía de "persuasión» para lograr que el monarca adoptase una decisión favorable -el matrimonio- a sus intereses. No obstante, no vamos a analizar esos escritos en este momento y sí vamos a pasar a otro factor que requiere nuestra atención.

Hay otro hecho en que ambos casos confluyen y, que está en relación con la «deshonra» sufrida por las damas. La consumación de estas relaciones ponía 
como única solución posible el matrimonio, un fin deseado por una y por otra. Conscientes de ello, ambas no dudan en aportar detalles sobre sus relaciones con los galanes. En la pormenorizada declaración de doña Luisa, la dama alude a los diferentes encuentros con don Gonzalo. Así, con motivo de la entrega de la Rosa de Oro a la reina doña Ana, que tuvo en las Descalzas su escenario privilegiado, doña Luisa y don Gonzalo concertaron una cita para hablar a través de la puerta del aposento de doña Ana de Cardona. El caso es que la situación devino de manera algo diferente ya que el caballero:

abrió con una daga y entró dentro del dicho aposento donde el dicho don Gonzalo tuvo acceso carnal con esta confesante y la desfloró y llevó su virginidad y tubo el dicho acceso carnal con esta confesante tres veces y esto pasó entre la una y las dos después de medio día.

Esta clase de episodios parece que se repitieron con ocasión de la salida de doña Luisa de Palacio. Primero cuando quedaron «solos en el dicho aposento del dicho guardajoyas...» y una vez llegados a la posada del caballero «se acostaron en la cama del dicho don Gonzalo esta confesante y él y, allí tuvo acceso con esta confesante el dicho don Gonzalo estando ambos desnudos en la dicha cama». Como vemos, doña Luisa es bastante prolija a la hora de señalar hasta qué punto era comprometida la relación con don Gonzalo. Evidentemente, y a la luz de sus declaraciones, ella no debió de considerar que era una falta tan grande pues ambos se consideraban casados pero, desde luego, la consumación del mismo era causa suficiente para que se mantuviese y aceptase tanto por parte del monarca, como por parte de la familia de don Gonzalo. Habría que señalar aquí la versión aportada por el propio caballero, quien, a pesar de no negar la consumación de la relación, difiere en algunos puntos. No podemos determinar aquí qué parte era la que contaba la verdad, pero debemos de pensar que, consciente de la gravedad del delito, don Gonzalo se guardó mucho de admitir los encuentros tanto en las Descalzas como en Palacio, si bien admitió que sí había tenido lugar uno en su propia casa ${ }^{25}$. Cambia asimismo la función de los roles; si en el caso de doña Luisa entendemos que la iniciativa correspondió a don Gonzalo, según el testimonio de este, el seducido fue él ya que en palabras suyas:

25. No es objeto de este estudio analizar pormenorizadamente el pleito contra don Gonzalo en su totalidad, pero sí que debemos señalar que el caballero fue muy cauto a la hora de relatar los hechos e, incluso, podemos ver un deseo de proteger a aquellas personas de su entorno que se vieron afectadas por él. Excusa a doña Luisa de Castro por las desavenencias en los testimonios -«tiene este confesante a la dicha doña Luisa por mujer de verdad, pero que en este negocio, la pasión y ser mujer la habrán hecho decir algo contra este confesante»- y trata de encubrir a sus deudos, así como a otros que le ayudaron en su tortuosa huída, como es el caso del duque de Medina de Rioseco. Confesión de don Gonzalo Chacón en Causa de don Gonzalo Chacón, op. cit., s. f. 
[hallándose] una noche del dicho mes de agosto (...) en su casa, algo mal dispuesto vio entrar por la puerta de un aposento alto donde este confesante dormía a la dicha doña Luisa de Castro su mujer como a las ocho y media o las nueve de la noche y cuando la vio este confesante se espantó y la dijo si era buen disparate aquel que le suplicaba que luego a la hora se volviese a Palacio que ella era mujer de este confesante, pero que no había de ser por aquel camino y procuró persuadirla por todas las vías posibles que se volviese a Palacio y la dicha doña Luisa dijo que estaba con su marido e que le avían dicho que estaba malo que iba a verle, y visto por este confesante que no aprovechaba lo que le avía dicho estuvo con la dicha doña Luisa como con su mujer y la conoció carnalmente y llevó su virginidad y allí la conoció solamente carnalmente e no en palacio ni en otra parte ninguna.

Parece, no obstante, que ante semejante situación la salida más honrosa para doña Luisa pasaba por la aceptación y confirmación del matrimonio, como a la postre sucedió. Por ello, no debe sorprendernos que doña Magdalena de Guzmán tratase de forzar la voluntad del rey de la misma manera. Si bien es cierto que en ninguna de las cartas que hemos comentado la dama alude a ello, podemos entender por las palabras de Antonio de Pazos que hizo una confesión semejante a la de doña Luisa. El presidente, en una de sus consultas al rey, dice lo siguiente:

en la misma carta que luego rompí me apunta a decir que ella tiene otras cosas secretas entre ella y don Fadrique, que nunca ha querido decir a V M ni a ninguna persona aunque fuera confesor por guardar el rostro a don Fadrique y por lo que conviene, de estas palabras se puede sospechar esto de la caída de Palacio o que entre ellos haya habido hechos más que palabras ni promesas, que entrambas cosas agravarían mucho el caso $^{26}$.

El monarca ordenó al presidente Pazos que lograra pruebas fehacientes del caso, ya que de otra manera la solución debía pasar por obligar a don Fadrique a que cumpliese la promesa hecha a la dama. Si esta era la intención de doña Magdalena, el resultado no fue el deseado y el presidente de Castilla, tras haber hecho las pesquisas necesarias, desestimó esta nueva confesión de la dama como «...engaño y muy contra la verdad» ${ }^{27}$. Sin entrar a considerar las razones por la cuales se desecharon las palabras de doña Magdalena, debemos reflexionar sobre el hecho de que la dama decidiese «deshonrarse» y verlo como una estrategia más.

26. El presidente Pazos a Felipe II, junio de 1578, Archivo General de Simancas [en adelante AGS] Patronato Eclesiástico, leg. 5, n. ${ }^{\circ} 199$.

27. El presidente Pazos a Felipe II, 7 de enero de 1580, recogido en CODOIN, vol. VIII. No obstante, las apreciaciones de Pazos no podemos dejar pasar por alto las apreciaciones que se vierten en la ya mencionada vida de Catalina de Cardona, donde se dice lo siguiente: «de tratar amores con las damas de su Casa y atreverse a dormir con ellas en Palacio como don Fadrique, duque de Alba había hecho con doña Magdalena en tiempo de la Reyna pasada y don Gonzalo Chacón con doña Luisa de Castro» De la buena mujer doña Catalina de Cardona... op. cit., fol. 73 v. 
La condición de doncellas tanto de doña Luisa como de doña Magdalena, convertía la consumación de las relaciones amorosas en un delito perfectamente tipificado en la legislación castellana del momento ${ }^{28}$. El estupro no era solo una falta de tipo moral, sino que acarreaba un componente delictivo, que debemos ver agravado por ser las damas criadas de su Majestad y estar bajo su tutela ${ }^{29}$. Este hecho no pasó desapercibido a ambos galanes y, si damos credibilidad a la acusación del Presidente Pazos, don Fadrique se cuidó mucho de no traspasar la frontera de las promesas verbales, pero no podemos afirmar lo mismo en el caso de don Gonzalo. Quizá este hecho nos permita hallar una explicación a la divergencia de testimonios aportados por ambos protagonistas; don Gonzalo coloca a doña Luisa como instigadora de la relación íntima, que además solo se limitó a una única vez en la posada del caballero. Negar la evidencia era algo que no podía hacer, y la noticia que se da más adelante en la confesión sobre la sospecha de un posible embarazo de doña Luisa, viene a corroborar estos hechos ${ }^{30}$. La comisión de tal delito exigía una reparación, y sin hablar de la dura condena que en un principio se sentenció, la ley establecía la compensación económica mediante la concesión de una dote, o bien la celebración del matrimonio restaurador de la honra. Y en este punto, es donde podemos volver a conectar con la idea expresada anteriormente, y que nos remite a la utilización de la «deshonra» por parte de ambas mujeres. doña Luisa contaba con una ventaja adicional, ya que sus interrogadores van a contar con una serie de pruebas fehacientes que complementaban su confesión. No parece así en el caso de doña Magdalena, quien tuvo que recurrir a la confesión y a las palabras veladas para tratar de sembrar la duda en aquellos que debían determinar su futuro. En su caso, evidentemente, tendríamos que tener en cuenta el precipitado

28. Véase BazÁn Díaz, I., «El estupro. Sexualidad delictiva en la Baja Edad Media y primera Edad Moderna» en Melanges de la Casa de Velázquez. Matrimonio y sexualidad. Normas, prácticas y transgresiones en la Edad Media y principios de la Época Moderna, 33:1, 2003, pp. 13-46. En él se analiza el delito sexual en su tipificación normativa, la definición de estupro y su realidad a través del análisis de casos concretos, donde se ve este delito bajo la óptica de la violencia y engaños sufridos por las mujeres pero, asimismo, la instrumentalización por parte de las mismas para obtener beneficios como la consecución de una dote o de un matrimonio.

29. En la confesión de don Gonzalo, el caballero relata cómo este hecho inhibió a alguno de sus conocidos-concretamente don Luis de Sotomayor y don Beltrán de la Cueva-a la hora de ayudarle y es que «se espantaban haber hecho un desatino tan grande e que era negocio que tocaba a su Majestad» Confesión de don Gonzalo Chacón, en Causa de don Gonzalo Chacón, op. cit., s. f.

30. En la confesión de don Gonzalo, los instructores utilizaron una serie de cartas que Don Gonzalo había enviado, durante su huída, a doña Luisa de Castro: «Fuele dicho que en la dicha carta dice este confesante lo siguiente, en my hijo no oso hablar, y fue preguntado qué es esto que este confesante dice del hijo en la dicha carta; dijo que este confesante oyó decir que la dicha doña Luisa estaba preñada y por esto lo dice» Confesión de don Gonzalo Chacón, en en Causa de don Gonzalo Chacón, op. cit., s. f. 
matrimonio de don Fadrique con doña María de Toledo y que acabó de manera fulminante con todas sus oportunidades de éxito.

\subsection{La apelación al Rey: el uso de la dialéctica del honor}

Cuando hablamos del honor en la España Moderna y lo analizamos desde una perspectiva de género solemos resumir que en el caso de las mujeres aquel estaba íntimamente unido al comportamiento sexual de las mismas. La preservación de la virginidad en las doncellas, así como la castidad de las mujeres casadas y viudas, eran fundamentales para su mantenimiento. En estos casos que estamos analizando hemos visto cómo el componente sexual va a tener una relevancia fundamental, y, además, ambas damas van a hablar sobre su comportamiento de una manera que llega a sorprender por su franqueza. En este punto, ya tenemos muy claro que la conducta de las mujeres del siglo xvi no se puede explicar a través de los textos normativos, ni siquiera, en muchos casos, a través de la voz de la literatura. Las fuentes documentales nos han demostrado, una y otra vez, que la realidad escapa de esos presupuestos teóricos que parecen enmarcar una sociedad, y que los comportamientos humanos se adaptan a las circunstancias del momento. La defensa del honor femenino tampoco es, necesariamente, una tarea masculina, $y$ sin lugar a dudas, los testimonios escritos de doña Magdalena de Guzmán y de su hermana, doña Brianda, son prueba suficiente de que las mujeres sabían utilizar la retórica del honor para la defensa de sus intereses particulares ${ }^{31}$.

Aunque cronológicamente las epístolas de doña Magdalena son posteriores a las de su hermana, vamos a empezar nuestro análisis por ellas. La lectura de estas misivas desesperadas que la dama envió a Felipe II entre 1578 y 1579 arrojan una serie de sensaciones al lector, que llega a sentirse conmovido por las palabras de la antigua dama. Por una parte, Magdalena va a incidir en su condición femenina y repite a lo largo de las diferentes cartas que ella es «una mujer y sola y tan afligida» ${ }^{32}$ que necesita de la ayuda del Rey para solucionar su situación. Si bien

31. En este sentido resulta tremendamente interesante la lectura de. TAYLOR, S. K.: Honor and Violence in Golden Age in Spain. Yale, 2008; en él se pone de manifiesto cómo las visiones sobre el honor que se translucen de la lectura de las obras teatrales del Siglo de Oro contrastan notablemente con la realidad. Con un estudio basado en fuentes archivísticas - muchas de ellas de tipo penal- da una visión más flexible sobre el concepto del honor y la instrumentalización de la dialéctica del honor. Véanse los capítulos 1 (pp. 1-16) y 5 (pp. 157-193). Asimismo, destacar otros trabajos que inciden en la elasticidad del concepto del honor en el periodo moderno; si bien determinadas acciones podían conducir a la «deshonra» de los individuos, también existían mecanismos a través de los cuales se producía su restauración: Twinam, A.: Vidas públicas, secretos privados. Género, honor, sexualidade ilegitimidad en la Hispanoamérica colonial. Buenos Aires, 2009; Barahona, R.: Sex Crimes, Honour and the Law in Early Modern Spain, Vizcaya 1528-1735. Toronto, 2003.

32. Carta de Magdalena a Felipe II, AGS Patronato Eclesiástico, leg. 5, n. ${ }^{\circ} 212$. 
aquí parece que lo que ella quiere primar es su debilidad y fragilidad, demuestra una cierta fortaleza y firmeza a la hora de recordar las obligaciones que el Rey tiene para con sus criados y que serían mucho más coercitivas que las que tendría para el conjunto de sus vasallos:

a mí que soy tan criada de $\mathrm{V}$ Majestad y que murió mi padre en servicio de $\mathrm{V}$ Majestad dejándome debajo de su amparo.

El objetivo sería conmover a Felipe II, a través de la dialéctica del honor, para la adopción de un rol de rey -juez compasivo y clemente que arbitrase una salida honorable para ella-. Evidentemente, ella acepta su parte de culpabilidad en todo el asunto, pero no deja de señalar que el mayor responsable fue don Fadrique, que incumplió su palabra de matrimonio. Su exilio forzado de la Corte alargado durante tantos años - «...ver que V M me tuviese tanto tiempo olvidada habiendo tanta razón y justicia de mi parte, y esto no un año sino trece»- la había señalado, a su juicio, como culpable de manera excesiva, de tal manera que le tocaba al Rey actuar y resolver la espinosa cuestión. Estos van a ser los argumentos principales que doña Magdalena va a repetir en esas mencionadas misivas. Por sí mismas ya gozan de suficiente entidad para entender el desenvolvimiento de los hechos que culminaron con su salida del cenobio toledano y su posterior matrimonio, pero no por ello debemos de olvidar las gestiones que su familia llevó a cabo para «limpiar» el buen nombre de la dama.

En el caso de doña Magdalena de Guzmán, sus hermanos gozaron de un especial protagonismo a la hora de defender su caso ${ }^{33}$. Encerrada en Toledo y con claros obstáculos -aunque no insalvables, como hemos visto- para proteger sus intereses, la dama tuvo que contar con su círculo familiar más cercano para evitar caer en el olvido y que su negocio quedase irresoluto. Su hermana, doña Brianda de Guzmán tuvo un papel fundamental en este sentido, ya que hizo uso de sus conexiones en la Corte para tratar de defender la difícil causa de su hermana. Hasta el momento presente hemos encontrado varios testimonios epistolares que

33. El Presidente Pazos hace alusión a las gestiones de los hermanos de doña Magdalena en uno de los despachos dirigidos a Felipe II: «Hoy ha venido aquí Juan de Guzmán, hermano de doña Madalena y me hizo mil exclamaciones sobre el negocio que le toca (...) antes de ahora doña Brianda hermana de doña Madalena antes de su partida me dijo que entre el duque y don Fadrique se trataba esto...» el Presidente Pazos a Felipe II, 11 de octubre de 1578, AGS, Patronato Eclesiástico, leg. 5, n. ${ }^{\circ}$ 216. La Propia doña Brianda menciona, por su parte, a otro hermano, Don Tello, que también tuvo un papel activo en la defensa de doña Magdalena «...como Tello de Guzmán mi hermano lo diría a V M» doña Brianda de Guzmán a Felipe II, 12 de enero 1573, BL Add Más. 28339, fol. 1. don Tello, aparece mencionado, asimismo, en la correspondencia dirigida por el Dr. Milio al duque de Alba «...diré aquí cómo D. Sancho de Padilla y Tello de Guzmán deben haber olido en los términos en que anda el negocio del Sr. D. Fadrique, y han hablado a su Mgd...» en Berwick y Alba, M. R.: Documentos escogidos del Archivo de la Casa de Alba. Madrid, 1891, p. 103. 
conciernen a la dicha doña Brianda; en primer lugar, una serie de cartas enviadas por don Juan de Zúñiga a esta señora y, por otro lado, varios memoriales que ella elevó a Felipe II. Si bien es cierto que los segundos nos ofrecen más informaciones sobre el caso de doña Magdalena, las primeras tienen su relevancia por las fechas en que están escritas -empezando en el año 1569 y acabando en 1581- así como por la presencia del mencionado don Juan de Zúñiga como valedor de esta familia.

Las cartas del entonces embajador de Felipe II en Roma nos ofrecen una valiosa información sobre las conexiones de los Guzmán en la Corte del Rey Católico. La complicada situación de doña Magdalena y los vínculos familiares de su galán hacían necesario tales contactos. Las cartas no nos permiten saber hasta qué punto don Juan de Zúñiga se implicó en la defensa de los intereses de doña Magdalena, pero sí que nos posibilitan conocer si se estaban haciendo gestiones o no para la resolución de la situación de la dama ${ }^{34}$. En su biografía sobre el gran duque de Alba, Maltby interpretaba el envío de los memoriales por parte de Magdalena a Felipe II como una maniobra auspiciada por la Princesa de Éboli y Antonio Pérez para perjudicar a su enemigo político en la Corte, don Fernando Álvarez de Toledo ${ }^{35}$; efectivamente, el largo lapso cronológico entre el estallido del escándalo y la reacción de la dama podía hacer pensar en que doña Magdalena pudo ser instrumentalizada para fines ajenos a su propio caso. Sin embargo, la correspondencia de don Juan de Zuñiga con doña Brianda nos sitúa en otro plano totalmente distinto en que vemos cómo la familia se movilizó rápidamente para tratar de solucionar la situación de la dama por la vía más lógica -el matrimonio-e incluso, podemos especular con la existencia de otras cartas de doña Magdalena al rey que quizá se hayan perdido o estén en fondos documentales todavía no explorados $^{36}$. Si bien don Juan de Zúñiga es muy lacónico en sus cartas de ánimo

34. Don Juan de Zúñiga contaba con unos cauces informativos muy interesantes, como es, por ejemplo, la correspondencia con el secretario del Rey Martín de Gaztelu, que le permitió conocer cómo se iban desenvolviendo los hechos en Madrid. Dicha correspondencia se halla en AMAEC, SS, leg. 4.

35. «La antipatía del rey por don Fadrique, reforzada con la acusación de ser el responsable de gran parte de los problemas de los Países Bajos, abrió las puertas a Pérez, que empleó la oportunidad para sus propios fines. Sintiéndose seguro gracias a la muerte de Escobedo, el secretario, junto a Ana de Mendoza, sacó a relucir el caso de doña Magdalena» MaLtby, William S.: El gran duque de Alba. Madrid, 2007 (1. ${ }^{a}$ ed. en 1983), p. 435.

36. Tenemos varias cartas fechadas en 1569 en que don Juan de Zúñiga hace referencia a doña Magdalena y a su difícil situación; así, hace referencia a los sentimientos que el conflicto en Flandes debía de generar en la dama «Bien creo que debe de hacer diferentes oraciones/ la señora doña Madalena por el suceso de la guerra de Flandes de las que debía de hacer ahora un año. Ruega a Dios que presto la vea yo con el consuelo que ha menester que en verdad se le deseo más que el mío", don Juan de Zúñiga a doña Brianda de Guzmán, 4 de marzo de 1569, BL Add Mss/28408 fols. 24r y v; así como su deseo de que todo el asunto se resolviese de manera satisfactoria. «Muy grande[merced] me la ha hecho $\mathrm{V} m$ en avisarme de que la señora doña Madalena esté tan buena, así sea muchos años 
a doña Brianda, sí que entendemos por las mismas que el proceso se detuvo en un momento dado y la solución ansiada por la familia Guzmán no llegó ${ }^{37}$. Eso nos lleva al año de 1573 cuando la hermana de doña Magdalena apeló al Rey a través de los memoriales citados para la resolución de una situación que en aquellos momentos se había alargado ya varios años.

Son cinco cartas en las que doña Brianda expone sus ruegos al monarca a quien conmina hacer justicia. Los argumentos que expone son muy interesantes y vamos a analizarlos uno a uno. En primer lugar doña Brianda -como posteriormente hará la propia doña Magdalena- recuerda la obligación que Felipe II tenía para con su criada y le recuerda los largos años de destierro a que se había visto sometida ${ }^{38}$. La situación de doña Magdalena resultaba así no solo incómoda para su propia familia, sino que también dañaba en cierto modo la reputación real, porque eran demasiados los años que habían transcurrido desde el incidente hasta el momento de la escritura de estas misivas. Doña Brianda abunda en los perjuicios que tal dilación habían tenido en su patrimonio y en su propia vida, aludiendo a su propia condición de «descasada» por la larga separación que ella misma sufría de su marido. Evidentemente la situación era muy compleja, porque como sabemos de por medio quedaba el propio conflicto surgido entre la otra parte, es decir la Casa de Alba, y la Corona. Hay que recordar que don Fadrique había sufrido una pena de destierro que finalmente había cumplido en los Países Bajos durante el mandato de su padre en aquellas provincias. En los momentos en que doña Brianda eleva sus peticiones a Felipe II, se estaba resolviendo el perdón de don Fadrique y ello explica por qué la familia de la dama se va a mover de manera insistente en estos precisos momentos ${ }^{39}$.

En segundo lugar, la remitente recordaba a Felipe II los servicios prestados por su familia a la Corona, un hecho que no duda en repetir en cada una de sus cartas, y que le lleva en la última de ellas a transmitir unos negocios de

y ruega a Dios que yo la vea con el contentamiento que merece» don Juan de Zúñiga a doña Brianda de Guzmán, 26 de mayo 1569, BL Add Mss/28408 fol. 66r.

37. En una carta del mismo año 1569 se hace referencia a ese parón «De sus negocios no se hoye por acá nada, antes parece que están olvidadas las pláticas de casamientos que anduvieron este invierno...» Don Juan de Zúñiga a doña Brianda de Guzmán, 1569, BL Add Mss/28408 fol. 90v.

38. «Yo vine de Toledo antes de Pascua dejando buena a doña Magdalena mi hermana y por no dar a V M pesadumbre no me voy a echar a sus pies suplicándole por Jesucristo se duela de mi hermana pues a diez años que la tiene V Md presa y mande acabar este negocio como de la Real Mano de V M esperamos» Memorial de doña Brianda de Guzmán a Felipe II, s. 1., 12 de enero de 1573, BL Add Mss 28339, fol. 1.

39. «Hoy he sabido que ay aquí nuevos despachos y papeles de don Fadrique para V Md y que el fraile de quien yo tengo avisado es solicitador de ello, deben de ser nuevas marañas y enredos del duque de Alba que por la gracia de Dios son bien hábiles en estas cosas y con dalles V Md tiempo le da todo lo que ellos pueden desear porque con ello se prometen muchas cosas» Memorial de doña Brianda de Guzmán a Felipe II, Madrid 15 de marzo de 1573, BL Add Mss 28339, fol. 3. 
interés para la Corona de parte de su marido don Sancho de Padilla ${ }^{40}$. Esta información que en el conjunto de las cartas puede parecer descontextualizada adquiere significado si se interpreta como un medio de hacer méritos ante la Corona para lograr una reparación conveniente y beneficiosa a los intereses de la familia Guzmán. Más allá de la importancia del linaje como servidor en las casas reales, doña Brianda responde al patrón habitual de comportamiento en estas circunstancias.

Uno de los puntos más interesantes que doña Brianda trata en una de sus misivas es el grado de compromiso que don Fadrique había contraído con su hermana siendo esta dama de Isabel de Valois. Según su versión, don Fadrique había dado su palabra de matrimonio a doña Magdalena en presencia de la reina, confirmando lo que ya había prometido por escrito y de palabra propia. La reina Isabel, por su parte, se habría comprometido a tratar este negocio con el rey, quien tenía la última palabra en este asunto ${ }^{41}$. Este hecho, si bien nos ayuda a reconstruir los prolegómenos del escándalo, también nos ofrece muchas incógnitas. La muerte de Isabel de Valois en 1568 había dejado sin testigos a doña Magdalena y a sus deudos, lo cual nos hace difícil corroborar estas informaciones vertidas por doña Brianda; no obstante, entendemos que fueron ciertas, pues habría otros -con más autoridad y poder en la Corte- que pudieran o bien respaldarlas o bien desecharlas. Por otro lado, surge la pregunta de si realmente la reina trató este asunto con Felipe II o no lo hizo, y en caso de habérselo transmitido, por qué el monarca no facilitó la consumación de este proyecto matrimonial. Evidentemente podemos trabajar con la idea de que la propia familia de don Fadrique estuviese obstaculizando todo el proceso desde su origen y que ello impidiese una resolución favorable para la dama.

Desde luego, doña Brianda no era ingenua en lo respectivo al comportamiento de la familia Alba, y alerta a Felipe II sobre las actuaciones semi-encubiertas del

40. Don Sancho de Padilla, muy vinculado a don Juan de Zúñiga, desarrolló gran parte de su carrera político-militar en Italia donde llegó a desempeñar el cargo de Castellano de Milán. Y como informa su mujer, «El capitán Aguirre a quien don Sancho mi marido enviaba con la planta del castillo y otros papeles que convenían al servicio de V M fue Dios servido que muriese en Zaragoza y yo como lo supe trabajé de cobrar la planta y los papeles que pude los cuales di al Secretario Gaitán y la planta tenía en mi poder hasta que V M viniese para entregársela porque esta orden me había dado mi marido, ahora me ha dicho el secretario Gaitán que se la dé que V M lo manda y así lo he hecho» Memorial de doña Brianda de Guzmán a Felipe II, s. 1.26 de Septiembre de 1573, BL Add Ms 28339 fols. 20-21.

41. «...suplico a V M se acuerde que don Fadrique de Toledo dio la palabra delante de la Reyna nuestra señora que esté en gloria a doña Magdalena su criada y allí en la propia presencia de la Reyna nuestra señora le prometió y dio palabra de que se casaría con ello y esto mismo le tenía él prometido antes por sus cartas y de palabra...» Memorial de doña Brianda de Guzmán a Felipe II, s. 1.17 de abril de 1573, BL, Add Mss 28339, fols. 7 y 8. 
Duque para evitar el matrimonio y casar a su hijo dentro de su propia parentela $\mathrm{a}^{42}$. A través de diversas personas, que actuarían como una red de influencias e informantes para la familia Guzmán, doña Brianda era partícipe de las gestiones para levantar el destierro a don Fadrique, así como las negociaciones del Duque con don García de Toledo para la conclusión del matrimonio con doña María de Toledo y Colonna, el cual gozaba de numerosas ventajas: don Fadrique casaba dentro de su familia, con una mujer de alto linaje y evitaba verse unido a doña Magdalena de Guzmán. La alarma de su hermana es, por tanto, comprensible y a través de su discurso -tremendamente crítico con la familia ducal-, alerta al rey sobre los perjuicios que la actitud del Duque pudiera tener no solo sobre doña Magdalena y su parentela, sino también sobre el propio monarca. En este punto debemos señalar que si bien es cierto que las palabras de doña Brianda estaban mediatizadas por los sufrimientos que el escándalo estaba causando a su casa, podemos concederle una visión bastante certera sobre el asunto ${ }^{43}$. La deriva posterior de este caso se tradujo en el desafío por parte del Duque al casar por su cuenta a don Fadrique sin contar con el visto bueno del rey y la caída en desgracia de la familia que se reparó, parcialmente, durante la campaña portuguesa.

Si bien es cierto que debemos vincular estas misivas con el devenir del otro hecho principal, esto es, el levantamiento del destierro de don Fadrique, surge un interrogante claro y es por qué Felipe II no actuó en 1573 y esperó hasta 1578 para tomar una resolución. Parece que las gestiones de doña Brianda no surtieron el efecto necesario, y fueron las misivas de doña Magdalena las que de nuevo pusieron sobre la mesa la necesidad de concluir con este negocio. No obstante, sí que resulta interesante ver el protagonismo que tuvo la hermana de la dama como defensora no solo de doña Magdalena, sino del honor de su casa.

42. «Así mismo hago saber a V M que tengo entendido que don García de Toledo a escrito a sr don Juan una carta para que suplique cierto particular a V M acerca de don Fadrique y de su hija el cual no he podido entender qué es más me temo no sea alguna maraña y diablura ordenada por estos venditos que en la otra vida no creo lo serán...» Memorial de doña Brianda de Guzmán a Felipe II, s. 1.26 de Septiembre 1573, BL Add Mss 28339, fols. $20-21$.

43. El propio don Juan de Zúñiga justifica los sentimientos de doña Brianda hacia la familia del Duque, si bien es cierto que le recomienda una cierta mesura: «Mucha merced me ha hecho V I con su carta de los 26 del pasado, y por ella he visto lo que ha habido en el casamiento de don Fadrique, y es cierto verdad que aunque yo no conociera/ a Vuestra Ilustrísima sólo por el valor con que se ha gobernado en este negocio la estimara y deseara mucho servir. Y como hasta aquí había Vuestra Ilustrísima lo que a su Cristiandad y autoridad convenía así ahora que el negocio no tiene remedio debría Vuestra Ilustrísima sacar de obligación a su marido y a sus hermanos con alzar del la mano y dejar a su Majestad el cuidado de lo que hubiere de hacer pues no se puede ya pretender más que venganza lo cual nos prohíbe la ley divina y la humana» don Juan de Zúñiga a doña Brianda de Guzmán, 7 de febrero de 1579, BL Add Mss/28411, fols. 192r y v. 


\subsection{La solución del conflicto: el matrimonio reparador}

El estallido de estos escándalos se vio seguido con los encierros de las damas en conventos toledanos, sin embargo, esta no dejaba de ser una solución provisional que debía subsanarse con otra más permanente: el matrimonio. Ya hemos visto antes cómo la mancha sobre la reputación y honra femeninas se limpiaba a través del matrimonio. En este sentido, el caso de doña Luisa de Castro y don Gonzalo Chacón tuvo una solución relativamente sencilla.

No he querido entrar a analizar pormenorizadamente todos los aspectos que encerró el proceso contra don Gonzalo Chacón, pero lo cierto es que su intento de huída se saldó con una investigación concienzuda, el proceso a otros personajes relevantes de la Corte e implicados en el suceso y la sentencia de una durísima pena contra el caballero ${ }^{44}$. Efectivamente, en un principio se condenó a muerte a don Gonzalo, pena que fue conmutada por la destierro previo matrimonio con la dama agraviada. Esta resolución tuvo lugar en 1575 y uno de los puntos fundamentales fue la privación de la encomienda de que disfrutaba el mencionado don Gonzalo ${ }^{45}$. Martín de Gaztelu da puntual noticia de estos hechos a don Juan de Zúñiga, y así sabemos que tras conocerse la nueva sentencia, don Gonzalo fue liberado de la Alameda, prisión donde había sido confinado, y desde allí fue a Toledo donde tuvieron lugar las velaciones. Unos días más tarde iniciaron el viaje de destierro que les condujo a Portugal ${ }^{46}$.

Si bien es cierto que la sentencia era bastante clemente con el caballero, la privación a que se veía sometido era muy grave, ya que le dejaba sin unos ingresos necesarios para su mantenimiento y el de doña Luisa de Castro. Doña María Chacón, que como hemos visto había sido parte importante de todo el asunto merced a su oposición a la relación de su hijo con la dama, tuvo que encargarse

44. «En el pleito de oficio de la justicia de que, por comisión de su Majestad, se conoce de la una parte y de don Gonzalo Chacón, preso en la fortaleza de la villa de la Alameda, de la otra. Fallamos que, por culpa que del proceso resulta contra el dicho don Gonzalo Chacón, debemos condenar y condenamos a que de la dicha fortaleza donde está preso sea sacado con voz de pregonero que manifieste su delito y de allí sea llevado al campo que está junto a la dicha fortaleza y sea degollado sobre un tapete de manera que naturalmente muera, más le condenamos en perdimiento de todos sus bienes que aplicamos para la cámara de su Majestad y mandamos que esta nuestra sentencia se ejecute luego y así lo pronunciamos y mandamos con costas» Causa de don Gonzalo Chacón en Causa de don Gonzalo Chacón, op. cit., s. f.

45. «S. C. R. M. El presidente de Órdenes don Antonio de Padilla me ha dado la sentencia que el Consejo de ellas ha pronunciado contra don Gonzalo Chacón por la cual le privan de la encomienda de Almodóvar para que V Md la provea libremente y de los frutos de ella que hubieren corrido aplicados a la cámara...» Gaztelu a Felipe II, Madrid 7 de febrero de 1575, Archivo Histórico Nacional [en adelante AHN], Consejos, leg. 15189, n. ${ }^{\circ} 12$.

46. Martín de Gaztelu a don Juan de Zúñiga, Madrid, s. f (hacia 1575) AMAEC leg. 4 nºs 199 y 200. 
de la preparación de un enlace que suponía, además, el destierro de la Corte de don Gonzalo ${ }^{47}$. Doña María, con la salud bastante quebrada en este momento, aun asumiendo la decisión real sobre su hijo va a tratar de evitar la salida de la encomienda de manos de su familia. Los testimonios del propio Gaztelu nos hablan del profuso agradecimiento de doña María al rey por esa pena más clemente que permitía a su hijo conservar su vida, aun cuando tuviese que abandonar la Corte, pero va a insistir en los graves perjuicios que la pérdida de ese beneficio generaba en su familia, por lo que elevará varios memoriales al Rey pidiendo su conservación para alguno de sus otros hijos ${ }^{48}$. A su muerte va a ser su hija, doña Luisa Chacón, la que tome el relevo en esas peticiones que no fructificaron ${ }^{49}$. No obstante, esto nos permite apreciar cómo la participación femenina va a ser crucial en estos casos de defensa de los intereses familiares. Al igual que hemos visto en el caso de doña Magdalena de Guzmán, la parentela va a actuar como una red coordinada que, vía memorial o vía contactos en la Corte, van a tratar de salvaguardar los intereses de los afectados, en este caso no de la dama, pero sí del galán implicado. Si bien es cierto que en su confesión don Gonzalo hace frecuente referencia a la oposición que su relación había generado en el seno de su familia hasta llegar a afirmar que «los mayores enemigos que tenía eran ellos», esta idea no se sostiene bajo ningún concepto. Fuese por la defensa del honor y reputación familiares, fuese por otras motivaciones de carácter más sentimental, la parentela de don Gonzalo se movilizó en su defensa y protección. Los casos de su madre y hermana son sumamente interesantes, pero no fueron los únicos. Los interrogadores ponen en tela de juicio las palabras de don Gonzalo al presentar como pruebas las misivas intercambiadas con su hermano, don Bernardo de Rojas, así como las apelaciones del caballero al marqués de Denia. Además, en la línea de los memoriales que hemos citado deberíamos tener en cuenta la carta enviada por el arzobispo de Sevilla y tío de don Gonzalo a la Princesa de Portugal para que esta

47. «...acuerdo a V Md como lo mando si se avisara a doña María Chacón o al marqués de Denia lo que se provee para que lo sepan y prevengan de lo necesario para el casamiento de don Gonzalo y de doña Luisa en Madrid» Gaztelu a Felipe II, Madrid 7 de febrero de 1575, AHN, Consejos, leg. 15189, n. $^{\circ} 12$.

48. Son dos los memoriales que eleva al Rey y en ellos doña María Chacón informa al Rey de su enfermedad y le pide que vele por sus hijos «Nuestro Señor ha sido servido de darme tal enfermedad que estoy más para la otra vida que para ésta y pues V Md sabe que mis hijos quedan sin ningún remedio yo muero tan pobre que nada les puedo dejar y su padre sirvió siempre en la casa de V Md», especialmente por su hija que, en aquel momento era dama de la reina Ana «A Ysabelica encomiendo mucho a V Md pues se ha criado en su casa y no le queda otro amparo en este mundo»; uno de los medios que propone es «V Md me conceda la merced que le suplico de esta encomienda» Memoriales de doña María Chacón a Felipe II, s. 1 y s. f, BL Add Mss 28341, fols. 232 y 234.

49. Memorial de doña Luisa Chacón a Felipe II, Add Mss 28341, fol. 196. 
actuase a favor del galán frente a Felipe II $^{50}$. Hay otro hecho que nos remite al papel de la parentela, y su capacidad para generar una respuesta exterior en ayuda de su linaje. Nos referimos a las cartas enviadas por la reina portuguesa, doña Catalina de Austria, a su embajador en Madrid para que intercediese por don Gonzalo y doña Luisa ante Felipe II. La reina se mostró muy activa para defender, en primer lugar, la vida de don Gonzalo -amenazada por esa pena capital-y después, para la conservación de la encomienda de Almodóvar en manos del caballero, ya que sin ella la pareja exiliada se hallaba sin sustento alguno. Catalina consideraba que la actitud clemente del Rey debía ponerse de manifiesto en este caso, entre otras cosas porque aquellos amoríos eran achacables a su juventud e inexperiencia ${ }^{51}$. La reina portuguesa actuaba para favorecer los intereses de la princesa doña Juana, pero también los de la familia Chacón-Sandoval, ya que no olvidaba los servicios que los marqueses de Denia habían realizado en la casa de Juana I de Castilla ${ }^{52}$.

Los memoriales de doña María y doña Luisa no tuvieron el efecto deseado y la familia no pudo resarcirse de aquella pérdida en otro miembro de la parentela. Pero volviendo al destino de la pareja protagonista, parece que la pérdida de esas rentas se tradujo en las previsibles dificultades y que quedan perfectamente descritas en un memorial que el propio don Gonzalo elevó a Mateo Vázquez en que habla de las deudas y penurias que sufría consecuencia de todos estos acontecimientos. Como ya se indicaba al principio, el caballero participó en la campaña de Alcazarquivir donde murió al lado del rey portugués.

En el caso de doña Magdalena y don Fadrique la resolución final resultó algo más farragosa por el matrimonio de aquel con doña María de Toledo. Independientemente de las resoluciones que Felipe II tomó en relación a don Fadrique y su padre -suficientemente conocidas- el monarca tuvo que arbitrar una salida honrosa para la dama, cuestión difícil en la que la edad de doña Magdalena, avanzada para los cánones de la época, constituía un inconveniente más a la hora de fijar su

50. Traslado de una carta que el arzobispo de Sevilla don Cristóbal de Rojas y Sandoval escribió a la serenísima Princesa Doña Juana sobre el negocio de don Gonzalo Chacón su sobrino, hijo de Don Hernando de Rojas, Sevilla 3 de Julio de 1573 BL, Add Mss/16176, fols. 166- 167.

51. «estos mozos, que ciegos de pasión, y deslumbrados con ella, y la mala sazón de su edad, y con las ocasiones que habréis entendido vinieron a dar en la desventura en que están» Carta de Catalina de Austria a su embajador, don Duarte de Castelo Branco, 22 de mayo de 1573, BA, 49-X-1 fols. $103 \mathrm{r}$ y v.

52. «Juntando con esto ser don Gonzalo Chacón nieto del marqués de Denia, a cuyas cosas por el servicio que hizo la Reina mi señora que esté en gloria, y a mí, conozco ser en obligación, y por ser hijo de Don Fernando de Rojas en quien siempre conocí mucho amor a mi servicio» Carta de Catalina de Austria a su embajador, don Duarte de Castelo Branco, 22 de mayo de 1573, BA, 49-X-1 fols. $103 \mathrm{r}$ y v. Sobre la relación con los Sandoval resulta de interés la lectura de Betahny Aram, La Reina Juana. Gobierno, piedad y dinastía. Madrid, 2001, concretamente el capítulo 5, pp. 195-240. 
destino. El resultado fue el enlace entre doña Magdalena y el marqués del Valle, que se efectuó bajo unas condiciones muy específicas. El marqués del Valle era viudo y contaba con un heredero varón, lo que hacía que, para él, el matrimonio no fuese imperativo. Sin embargo, la promesa de la grandeza fue una oferta lo suficientemente tentadora como para que se resolviese a contraer estas nuevas nupcias ${ }^{53}$. El matrimonio solucionaba de manera bastante honorable la situación de doña Magdalena, la cual no dejó de defender sus intereses en las circunstancias que lo requirieron ${ }^{54}$. Se abría una nueva fase en la vida de la flamante marquesa del Valle que, podemos considerar, culminó durante el reinado de Felipe III cuando su carrera cortesana se consolida -aunque brevemente- como aya de la infanta doña Ana. A pesar de los problemas que va a tener que vivir en estos años, doña Magdalena no salió demasiado mal parada de su escándalo de juventud, si bien no podemos negar que el camino que tuvo que recorrer fue tortuoso y muy largo.

\section{Conclusiones}

Aquí se han delineado dos casos particulares que nos permiten reflexionar sobre la compleja realidad de las sociedades pasadas y, más concretamente, del mundo cortesano. Estudios como los de Magdalena Sánchez, que ponían el énfasis en el entorno femenino más cercano al poder, mostraban la necesidad acuciante de volver a analizar las fuentes para comprender en su justa medida el papel de las mujeres en el ámbito de la Corte. En este sentido las vidas de doña Luisa de Castro y doña Magdalena de Guzmán nos muestran cómo las mujeres del siglo xvi contaron con estrategias de actuación que les permitieron defender sus intereses particulares y resolver con una cierta solvencia estas situaciones que podemos calificar de dramáticas. Sus casos solo son una muestra en un panorama tan complejo como la Corte de los Austrias, de ahí que sea necesario seguir trabajando en trayectorias vitales específicas.

Los casos particulares nos conducen en ocasiones hacia la excepcionalidad y, evidentemente, no podemos pensar que todas las damas se hubiesen comportado

53. Los problemas que tuvieron que afrontar los marqueses del Valle en relación a la concesión de su grandeza son los que nos dan una información precisa acerca de las premisas bajo las cuales se asentó su matrimonio: «venga en el negocio sin condición alguna sino que vaya por vía de trato y concierto y le concede (como le tuvo concedido el año de 62) título de Grande pues concurren en su persona, casa y hacienda las partes requisitas tan bastantemente como en todos los del Reino y haberse prometido con tantos respectos a quien casare con doña Magdalena está presto para lo efectuar». Y es que, el marqués, como muy bien declara en este matrimonio lo hacía bajo esa condición ya que «la suya no era de casarse», Memorial del marqués del Valle, s. a (aprox. 1583) BL Add Mss 28344, fol. 383 .

54. Nos referimos a una serie de memoriales que la entonces marquesa del Valle elevó a Felipe II pidiendo que la prometida grandeza se efectuase y conservados en BL Add Mss 28343, fols. 16 y 19. 
de manera similar en circunstancias parecidas. No obstante, entendemos que el estudio de los mismos tiene que arrojar, por fuerza, una visión más certera y clarificadora sobre el mundo social de la Corte. Las fuentes archivísticas aportan una multitud de ejemplos que deben y merecen ser analizados; se trata de otorgar voz a aquellas que, por suerte, han dejado un rastro documental tras de sí y, a la vez, incorporarlas al discurso histórico. Estas mujeres que poblaron la Corte de Felipe II no son meros apéndices de los varones que las rodearon, son seres autónomos que supieron actuar y manejar los recursos a su disposición para moverse en un escenario complejo, interactuando en los círculos femeninos que habitaban de continuo, pero también en aquellos que compartían con los hombres. El matrimonio, la construcción de redes sociales, la defensa de los intereses familiares, son aspectos en los que ellas, al igual que ellos, tienen un protagonismo que debemos poner de relieve. En este caso concreto hemos analizado el proceder de dos damas -y su círculo más inmediato- en asuntos relacionados con matrimonios ilícitos, pero hay muchísimas otras casuísticas en que protagonizan los hechos ${ }^{55}$. Conocer sus actuaciones y estrategias no solo redunda en un mayor conocimiento del particular universo femenino que conformaba la Corte, sino también en tener una mejor comprensión sobre la sociedad del siglo xvi y el rol femenino en ella.

\section{BibLIOgRAFÍA}

Alvar Ezquerra, A.: La villa de Madrid vista por los extranjeros, Madrid, 1990.

ArAm, B.: La Reina Juana. Gobierno, piedad y dinastía, Madrid, 2001.

BAZÁn DíAz, I: «El estupro. Sexualidad delictiva en la Baja Edad Media y primera Edad Moderna", Melanges de la Casa de Velázquez. Matrimonio y sexualidad. Normas, prácticas y transgresiones en la Edad Media y principios de la Época Moderna 33:1 (2003), pp. 13-46.

Berwick y Alba, M. R.: Documentos escogidos del Archivo de la Casa de Alba, Madrid, 1891.

BRUCKer, G.: Giovanni y Lusanna. Amor y matrimonio en el Renacimiento, Madrid, 1991.

Candau Chacón, M. L.: «En torno al matrimonio: mujeres, conflictos, discursos», en PeÑa Díaz, M. (coord.): La vida cotidiana en el mundo hispánico: (siglos XVI-XVIII), Madrid, 2012, pp. 97-118.

55. Algunas contribuciones han reseñado este protagonismo femenino; por ejemplo, podemos hacer referencia a las contribuciones presentes en la obra colevtiva dirigida por NADER, H. (ed.): Power and Gender in Renaissance Spain. Eight Women of the Mendoza Family, 1450-1650. Chicago, 2004; en el caso de aquellas mujeres muy cercanas al espacio cortesano queremos poner el énfasis en aquellos que se centran en la influencia política de las mismas; la regencia de Mariana de Austria fue, en este sentido, un periodo único y que ofrece casuísticas muy particulares: Oliván SANTALIESTRA, L. «La dama, el aya y la camarera: perfiles políticos de tres mujeres de la Casa de Mariana de Austria» en Martínez Millán, J. y Lourenço, M. P., (coords.), op. cit., pp. 1301-1356. 
ELISA GARCÍA PRIETO

«DONDE AY DAMAS, AY AMORES». RELACIONES ILÍCITAS EN LA CORTE DE FELIPE II: EL CASO DE DON GONZALO CHACÓN Y DOÑA LUISA DE CASTRO

Cruz Medina, V.: Cartas de Ana de Dietrichstein a su madre, Margarita de Cardona: una doncella en la Corte de Felipe II (1573/4-1581), (Trabajo de investigación), Madrid, 2002.

Dadson, T. J.: «Un poeta del amor y los amores de un poeta: Diego de Silva y Mendoza, conde de Salinas (1564-1630)», en CERDAN, F., Hommage à Robert Jammes, Toulouse, 1994, pp. 299-311.

Fernández Martín, L.: «La marquesa del Valle. Una vida dramática en la Corte de los Austrias», en Hispania 39, (1979), pp. 559-638.

Feros, A.: El duque de Lerma. Realeza y privanza en la España de Felipe III, Madrid, 2002.

Hammer, P. E. J.: «Sex and the Virgin Queen: Aristocratic Concupiscence and the Court of Elizabeth I», en Sixteenth Century Journal, XXXI:1 (2000), pp. 77-97.

Kamen, H.: The Duke of Alba, New Haven-Londres, 2004.

López Cordón Cortezo, M. V.: «Entre damas anda el juego: las camareras mayores de Palacio en la Edad Moderna», Cuadernos de Historia Moderna, Anexo II, (2003), pp. 123-152.

Maltby William, S.: El gran duque de Alba, Gerona, 2007 (1ª ed. en 1983).

Martínez Hernández, S.: «Estrategias matrimoniales en tiempos de disfavor regio: juicio, prisión y muerte de Don Fadrique de Toledo, IV duque de Alba, 1574 1585», en Ser Quijano, G. (coord.): Congreso V Centenario del III duque de Alba, Fernando Álvarez de Toledo, Salamanca 2008, pp. 499-523.

Martínez Hernández, S.: Rodrigo Calderón. La sombra del valido. Privanza, favor y corrupción en la corte de Felipe III, Madrid, 2009.

Martínez Millán, J. y Fernández Conti, S. (dirs.): La Monarquía de Felipe II: la Casa del Rey, Volumen II, Madrid, 2005.

Martínez Millán, J. y Lourenço, P. M. (coords.): Las relaciones discretas entre las Monarquias Hispana y Portuguesa: las Casas de las Reinas (siglos XV-XIX), Madrid, Polifemo, 2008.

Milán, L.: Libro de motes de damas y caualleros, intitulado el juego de mandar, Valencia 1535.

Morant Deusa, I. y Bolufer Peruga, M.: Amor, matrimonio y familia, Madrid, 1998.

Nader, H. (ed.): Power and Gender in Renaissance Spain. Eight Women of the Mendoza Family, 1450-1650, Chicago, 2004.

Olivari, M.: «La marquesa del Valle: un caso de protagonismo político femenino en la España de Felipe III», en Historia Social, 57, (2007), pp. 99-126.

SAN Román, A.: Iornada y muerte del Rey Don Sebastián de Portugal, sacada de las obras del Franchi ciudadano de Génova y de otros muchos papeles auténticos, Valladolid, 1603.

SÁnchez, M. S.: The Empress, the Queen and the Nun. Women and Power at the Court of Philip III of Spain, Baltimore, 1998.

TAYlor, S. K.: Honor and Violence in Golden Age Spain, New Haven-Londres, 2008.

Vega Vázquez, I. (ed.): El libro de motes de damas y caballeros de Luis de Milán, Santiago de Compostela, 2006. 
Wall, A., «Love, Money or Politics? A Clandestine Marriage and the Elizabethan Court of Arches», The Historical Journal, 38:3, pp. 511-533.

Williams, P.: El gran valido. El duque de Lerma, la Corte y el gobierno de Felipe III. 1598-1621, Valladolid, 2010. 